\title{
LICENCIATURA EM EDUCAÇÃO DO CAMPO: A PERCEPÇÃO DE UNIVERSITÁRIOS SOBRE A DISCIPLINA DE LIBRAS
}

\author{
RURAL EDUCATION TEACHER TRAINING: UNIVERSITY STUDENTS' \\ PERCEPTION ABOUT THE LIBRAS DISCIPLINE
}

Carlos Antônio Cunha dos Santos *

\begin{abstract}
Resumo
O objetivo deste trabalho é registrar a percepção de estudantes de uma turma do curso de Licenciatura em Educação do Campo em relação à disciplina Introdução ao Ensino de Libras. Aplicou-se um questionário para se investigar as principais barreiras para a inclusão de aluno surdo em sala de aula e a pesquisa mostrou que a maioria desses alunos tiveram contato inicial com a Libras na escola, mesmo quando havia a presença de um familiar surdo em casa. $\mathrm{O}$ processo de inclusão desses alunos não acontece como estabelecido pela legislação brasileira, sobretudo, devido à carência de profissionais da Libras e de formação docente adequada para atuar com os alunos surdos. Observou-se também que, embora a carga horária atenda à legislação vigente, essa é insuficiente, pois não possibilita a aplicação dos conteúdos previstos na ementa do curso, tornando-se um dos entraves para melhor aproveitamento da disciplina.
\end{abstract}

Palavras-chave: Libras. Educação do Campo. Graduação. Inclusão.

\section{Introdução}

A regulamentação da Lei $n^{\circ} 10.436$, através do Decreto $n^{\circ} 55.626$, tornou Libras disciplina curricular obrigatória nos cursos de formação de professores para o exercício do magistério, em nível médio e superior. A disciplina também é obrigatória nos cursos de Fonoaudiologia, nas instituições de ensino públicas e privadas, sendo optativa nos demais cursos de Educação Superior e na Educação Profissional (BRASIL, 2005). Treze anos depois de a legislação entrar em vigor, período suficiente para que $100 \%$ das instituições se adequassem à legislação, muito ainda se discute em torno do que é necessário para que haja uma verdadeira inclusão do sujeito surdo nos espaços da educação brasileira. Uma das frentes em debate é a que trata da formação de futuros professores.

\footnotetext{
* Especialista em Educação Ambiental e Sustentabilidade, Pedagogo, biólogo, professor do Ensino Básico, Técnico e Tecnológico - IFPA, Campus Rural de Marabá (CRMB). E-mail: carlos.antonio@ifpa.edu.br
} 
Vitaliano (2009, p. 2) afirma que os professores atuantes em todos os níveis de ensino não estão preparados para incluir alunos com necessidades especiais. Da mesma forma, os cursos que formam professores, em sua maioria, ainda não propiciam formação adequada. Seguindo essa linha, Guarinello et al. (2006) aponta que a inclusão de surdos no ensino regular significa mais do que apenas criar vagas e proporcionar recursos materiais. Requer uma escola e uma sociedade inclusiva, que assegurem igualdade de oportunidades a todos.

A crítica reside no fato de que o processo de ensino-aprendizagem de uma segunda língua não pode estar calcado exclusivamente em ensino de vocabulário. O futuro mestre precisa dominar os processos discursivos muito além de um ensino baseado em um "manual rápido" da aprendizagem da Libras, pois tem sido assim o ensino da disciplina nos cursos de licenciatura e magistério. Começam as críticas pela denominação que a disciplina recebe: Introdução ao Ensino de Libras, Introdução à Libras. Trata-se de uma disciplina introdutória que, geralmente, é apresentada de forma superficial. Outro problema é a sua carga horária, não mais que 60 horas na composição curricular. Quando são analisados os currículos dos cursos que formam professores para educação básica, é possível observar que, tanto os professores das disciplinas de Língua de Sinais quanto as ementas dessas disciplinas não condizem com as necessidades requeridas para a formação do professor de alunos surdos.

Constata-se, nesse cenário, que as propostas de ensino voltadas à inclusão dos surdos não têm atendido, de forma plena, as necessidades desses alunos, deixando lacunas, principalmente no quesito interação. Muitos graduandos reconhecem essa falha pois, na verdade, professores e alunos continuam sem saber como agir diante da presença de um aluno surdo em sala de aula. Souza (2016), explica que isso ocorre porque a disciplina acontece em um único semestre de todo o curso da graduação, e pretende atuar como um manual de inclusão dos surdos na escola e na sociedade. O fato é que esses esforços não estão sendo suficientes. $\mathrm{O}$ Projeto Político Pedagógico do Curso de Graduação em Licenciatura Plena em Educação do Campo, (2007, p.14), Área de Concentração: Ciências Humanas e Socias, do Plano Nacional de Formação de Professores do Estado do Pará, cita o segundo parágrafo do artigo 12 das Diretrizes Nacionais da Educação Especial na Educação Básica, que assegura ao aluno surdo o direito ter acesso aos conteúdos curriculares por meio da Língua de Sinais. Para que isso fosse possível, contudo, o professor da Educação Básica deveria, obrigatoriamente, adquirir tais conhecimentos. 
Essa exposição pretende demonstrar que é necessário ir além de uma simples "introdução" ao ensino de Libras, de um manual rápido de aprendizagem que só conduzirá a um conhecimento superficial dos conteúdos necessários à formação de um professor que se torne capaz de incluir o surdo em sala de aula.

Por isso, o presente estudo buscou conhecer a percepção de estudantes do curso de Licenciatura em Educação do Campo em relação à disciplina de Libras. Além disso, procurouse detectar os principais entraves e lacunas dessa disciplina na visão dos universitários, especialmente quando se fala em formação de professores inclusivos.

\section{Revisão de literatura}

A discussão sobre a formação de professores para inclusão do aluno surdo tem ganhado espaço na educação brasileira, sobretudo a partir da regulamentação da Lei de Libras pelo Decreto 5.626/05. A Libras passou a ser disciplina obrigatória dos currículos de todos os cursos de Educação Especial, Fonoaudiologia e Magistério em nível médio e superior (BRASIL, 2005). Antes, o reconhecimento legal da Língua Brasileira de Sinais, através da lei 10.436/02, já havia conduzido a um processo de discussões e de movimentações, as quais culminaram em determinações políticas que viriam a impactar os processos de formação de professores de todas as áreas do conhecimento. É oportuno lembrar que, em tempos remotos, predominava a comunicação gestual, que foi gradativamente substituída pela comunicação oral. Essa observação de Vygotsky é retomada por Reily (2004, p. 113), que afirma:

Vygotsky escreveu que os homens pré-históricos trocaram a
comunicação gestual pela comunicação oral, pela palavra, quando
começaram a utilizar ferramentas; trabalhando, com as mãos
ocupadas, precisaram inventar uma alternativa para dialogar. Essa
ideia ressalta a naturalidade da interação pela linguagem das mãos
e, de certa forma, explica por que o movimento contrário (da
linguagem oral para a gestual) é um processo reinventado na
história dos grupos sociais com tanta frequência, quando a
situação exige.

É justo que toda uma mobilização seja efetuada para garantir o acesso do surdo à educação. Para receber os alunos deficientes auditivos, da educação básica ao ensino da graduação, são contratados tradutores e intérpretes de Libras, entre outras providências. As instituições federais de ensino devem garantir a essa clientela acesso à comunicação, à 
informação e à educação nos processos seletivos, nas atividades e nos conteúdos curriculares, desenvolvidos em todos os níveis, etapas e modalidades de educação, desde a educação infantil até à superior (BRASIL, 2005). Na perspectiva da inclusão, as políticas inclusivas têm surtido efeito. Segundo dados do Censo Escolar MEC/INEP (BRASIL, 2016), houve evolução no número de matrícula de alunos surdos no ensino comum da Educação Básica. Dos 56.024 alunos surdos matriculados em 2003, passou-se para 64.348, no ano de 2015, o que expressa um crescimento de aproximadamente $15 \%$.

Na formação de professores para Educação do Campo, por exemplo, o Projeto Político Pedagógico (PPP) do curso prevê a disciplina denominada "Introdução ao Ensino de Libras", com carga horária de 60 horas, sendo $80 \%$ dessas horas distribuídas no Tempo Escola e o restante na Alternância Pedagógica (Tempo Comunidade). A ementa aborda os seguintes conteúdos: Aspectos históricos, culturais, linguísticos e sociais das pessoas com surdez; Libras como fator de inclusão da pessoa surda; Língua brasileira de sinais no contexto da política e legislação possibilitando ao professor conhecimentos básicos para a intervenção no processo de inclusão do aluno do campo; Estrutura gramatical; datilologia ou alfabeto manual; Parâmetros primários e secundários; Produção, recepção; Números; Vocabulário do cotidiano e atividades práticas. A disciplina foi pensada "no âmbito do atendimento às pessoas com Necessidades Especiais (PNEES), utilização de equipamentos específicos como recursos didático-pedagógicos" apropriados (PPP, 2007, p. 165).

Mesmo assim, com recursos didáticos e metodológicos adequados, como livros didáticos voltados para a cultura surda, um breve estudo sobre a Libras e a Datilologia (alfabeto manual), o conteúdo ofertado é muito superficial. A discussão não é sobre a grande quantidade de conteúdo, ou o pouco tempo para desenvolvê-lo, na maioria das vezes, diante de um aluno que nunca foi apresentado às línguas de sinais. A grande questão é como fazer o ensino de Libras se tornar funcional no processo pedagógico, obtendo sucesso ao preparar o futuro professor.

Martins (2008, p.195) reforça a percepção de que pode se tornar "superficial o ensino da língua de sinais, tomando uma única disciplina semestral, como manual de inclusão dos surdos na escola e na sociedade". Mesmo assim, a disciplina parece atender a proposta do Decreto $\mathrm{n}^{\circ} 5626 / 055$, é o que afirma Mercado (2012, p. 62), ao analisar os planos dessa 
disciplina, referentes ao ano de 2009, em cinco cursos de Pedagogia de instituições privadas de ensino superior da grande São Paulo.

De acordo com Rossi (2010, p. 70) o Decreto Federal $n^{\circ}$ 5.625/2005 considera a dimensão linguística para a inclusão do aluno surdo na escola regular, tendo em vista que obriga a inserção da disciplina de Libras nos cursos que formam professores. A inserção da disciplina de Libras nos cursos de licenciatura foi um grande passo rumo à efetivação da inclusão, considerando-se que ter uma língua compartilhada entre professor e aluno é fundamental para que haja aprendizagem. No entanto, só essa inserção de disciplina não garante a inclusão. Além disso Rossi ressalta que o Decreto não menciona como essa disciplina deve ser aplicada, não define os conteúdos ensinados, nem os objetivos ou a carga horária.

Enquanto isso, a disciplina de Introdução à Libras permanece um campo de debates e desafios para as instituições educacionais. Além dos desafios estruturais, físicos, avolumam-se os desafios humanos, dentre os quais a formação de professores, que se constitui a célula-mater desse processo. A providência de mudar somente o currículo não trará soluções. Ações e mudanças devem ocorrer com o foco na capacitação dos professores, a adequação do currículo escolar e a inclusão da Libras como componente curricular obrigatório, não somente nos cursos de licenciatura, mas também na educação básica, como afirma Lourenço (2017), tornando bilíngue a sociedade brasileira, com vista à comunicação entre surdos e ouvintes. É importante lembrar que, ainda que a Constituição indique a presença de tradutores e intérpretes de Libras nas instituições educacionais, o ensino da Língua Brasileira de Sinais ainda não é componente curricular obrigatório na educação básica.

\section{Procedimentos metodológicos}

$\mathrm{Na}$ coleta de dados para este estudo, foram utilizados questionários direcionados a alunos de graduação, no final do primeiro semestre do curso, após terem cursado a disciplina "Introdução ao Ensino de Libras". Participaram da pesquisa 50 alunos da Licenciatura em Educação do Campo do Instituto Federal do Pará, Campus Rural de Marabá. Todos responderam ao questionário, formulado com perguntas abertas e fechadas (Marconi \& Lakatos, 2010), sobre gênero, idade, cor, conhecimento da Libras, locais onde tiveram contato com a língua, presença ou não de surdo familiar, processo de inclusão, avaliação da carga 
horária e sobre como se sentiam em relação à presença de aluno surdo em sala, após cursarem a disciplina de Libras.

As questões foram elaboradas visando esclarecer se a disciplina de Libras, nos cursos de licenciatura em geral e, em particular, no curso Educação do Campo, oferece de forma satisfatória conhecimentos básicos de Libras e se a obrigatoriedade da disciplina de Libras nos cursos de formação de professores elimina a insegurança desses futuros profissionais em trabalhar com alunos surdos. Além disso, a pesquisa procurou determinar se a disciplina contribuiu na formação desses futuros educadores, diante do atual cenário de valorização da inclusão, sobretudo quanto ao deficiente auditivo em sala de aula.

Os dados coletados foram categorizados e analisados através de tratamento estatístico adequado utilizando testes como o Qui-Quadrado, a fim de revelar a existência ou não de diferenças significativas em relação à opinião de alunos do gênero masculino e feminino. Houve ainda a utilização do programa Bioest 5.3, versão atualizada, um programa gratuito para estudantes de graduação e pós-graduação, pesquisadores e professores, voltado sobretudo para as áreas das ciências biológicas e médicas.

\section{Análise e discussão dos resultados}

Os dados do questionário aplicado foram tabulados, categorizados, sistematizados e apresentados através de planilhas eletrônicas e gráficos, mostrando o panorama atual do cenário diagnosticado pelos universitários em relação à disciplina de Libras no curso de licenciatura.

\subsection{Perfil dos graduandos}

A turma de Licenciatura em Educação do Campo-2018, do IFPA, Campus Rural de Marabá (CRMB) é composta por 60 alunos. Desses estavam presentes 50, que responderam ao questionário. Dos participantes, 35 são do sexo feminino, 15 do sexo masculino. Esse resultado

expõe uma tendência aproximada, confirmada pelas últimas amostras dos indicadores do Ensino Superior brasileiro, pois 71,7\% das matrículas em cursos de licenciatura são do sexo feminino, enquanto 28,9\% são do sexo masculino (BRASIL, 2016). A idade dos graduandos variou dos 17 aos 49 anos, com média de 27 anos e a moda de 20 anos (Figura 1). Se autodeclararam pardas $80 \%$ (40 pessoas), $16 \%$ pretas ( 8 pessoas), branca $2 \%$ (uma pessoa) e amarela $2 \%$ (uma pessoa). 
Figura 1. Mostra os intervalos de idade dos participantes da pesquisa

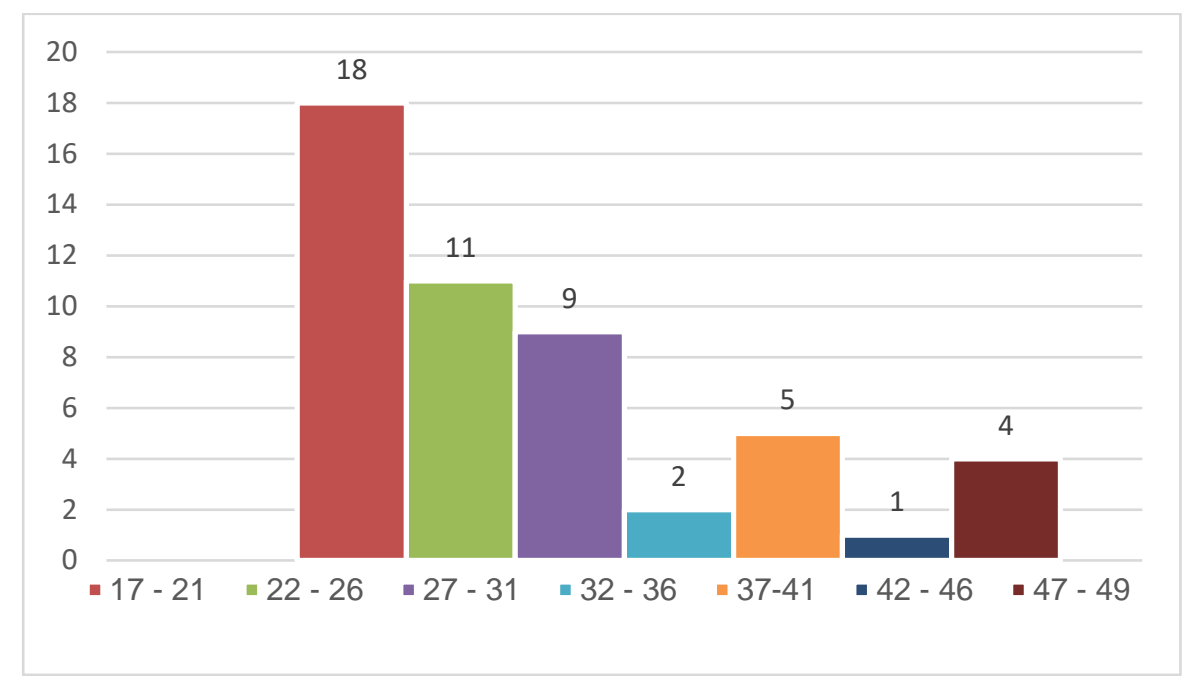

Fonte: elaborado pelos autores com base nos dados da pesquisa.

\subsection{Libras, o processo de inclusão e formação docente}

Quando indagados se conheciam a Libras antes de cursarem a disciplina na graduação, apenas 18 estudantes responderam que sim. Desses, a metade teve contato com a língua dos surdos na escola, 5 em outros locais não especificados no questionário, 2 em casa, devido à presença de familiar surdo no ambiente familiar, que usava a Língua de Sinais. Os demais locais para contato inicial com Libras, citados pelo menos uma vez, foram: a faculdade e algum movimento social (Figura 2). Os resultados mostram que mesmo não sendo disciplina obrigatória na educação básica, a escola tem um papel importante na divulgação e na aquisição da Libras, pois é onde a maioria das pessoas tem um contato mais próximo com a língua de sinais, mesmo aqueles com familiares surdos em casa. 
Figura 2. Locais onde os graduandos tiveram o primeiro contato com a Libras.

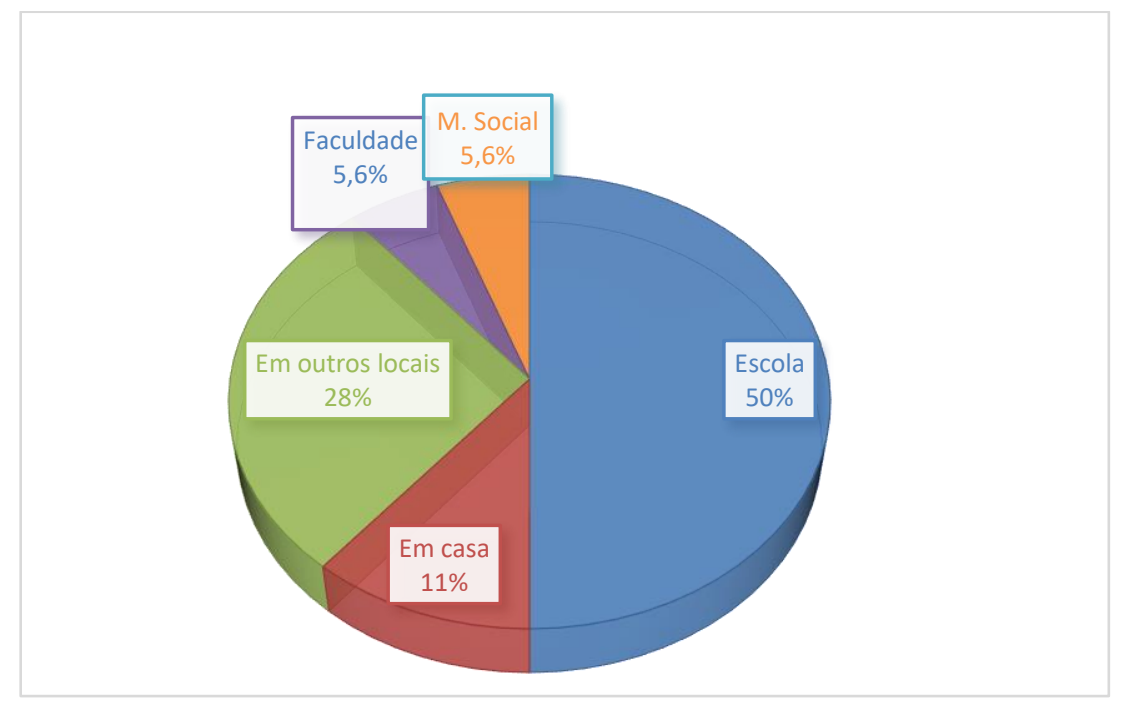

Fonte: elaborado pelos autores com base nos dados da pesquisa.

Sobre o processo de inclusão nas escolas brasileiras, se atende ao que prevê a legislação, 44 acadêmicos disseram que não $(88 \%)$, dando as mais diversas justificativas para suas respostas. Mesmo se tratando de uma explicação em que o pesquisado poderia citar uma infinidade de situações foi possível enumerar as respostas com as críticas mais comuns como, por exemplo, falta de profissionais na área de Libras, incluindo professores capacitados e intérpretes com $46 \%$ das respostas, tendo sido a principal reclamação. Seguida pela exclusão do surdo na sociedade bem como pelas políticas públicas com $25 \%$, pelas barreiras que dificultam a acessibilidade surda (14\%), falta de investimentos em diferentes espaços físicos com $10 \%$ e a política de inclusão que não acontece de fato (5\%), como retratadas na Figura 3. 
Figura 3. Razões de o processo de inclusão não atender ao que prevê a lei, na ótica dos estudantes.

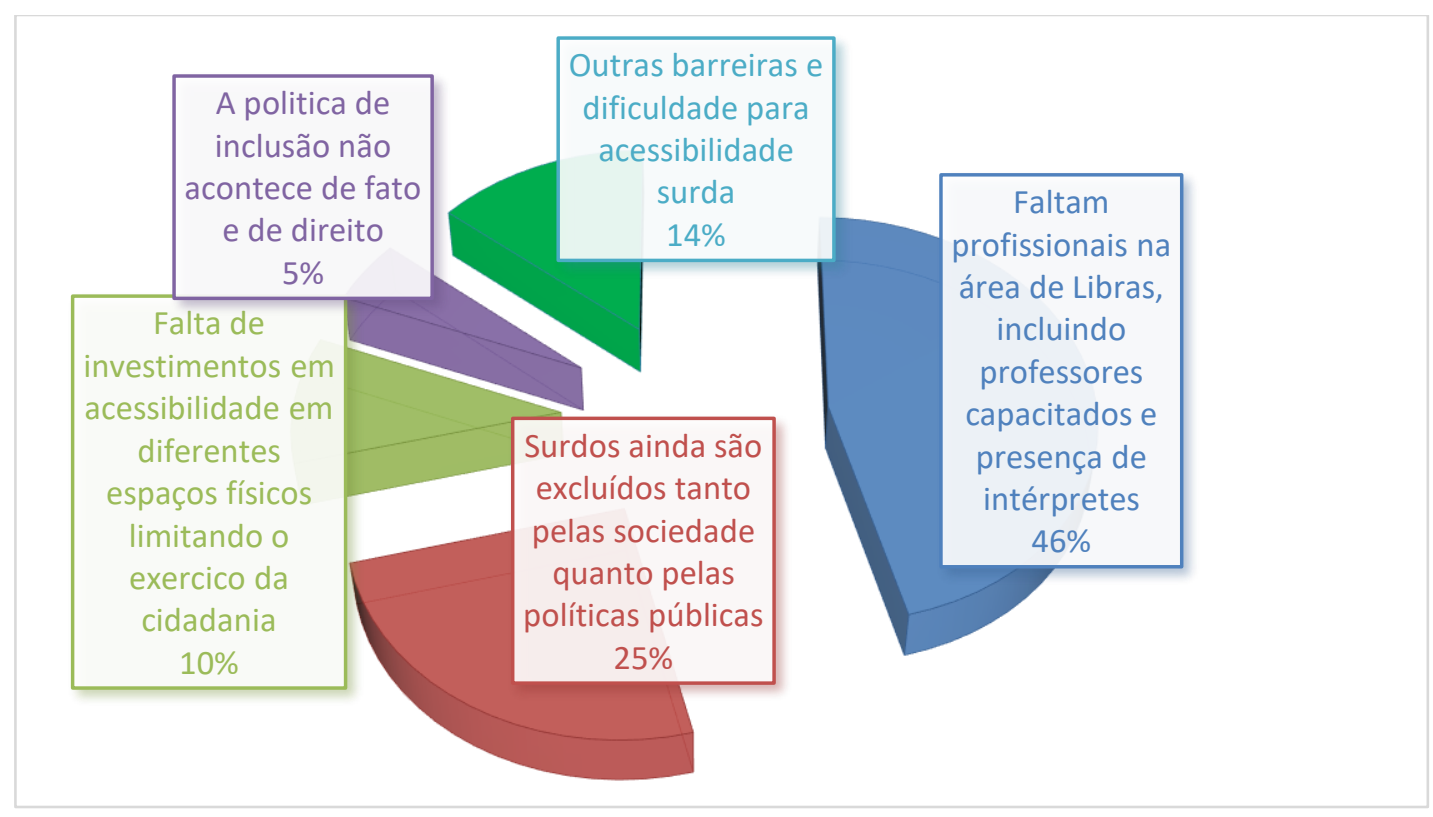

Fonte: elaborado pelos autores com base nos dados da pesquisa.

Esses resultados denunciam, na visão dos graduandos, alguns fatores que ainda impedem a inclusão dos surdos. Nesse sentido, a capacitação e preparação pedagógica apropriada de intérpretes, seguidos pelo preconceito da sociedade e a falta de políticas públicas, são agentes que interagem e contribuem nesse processo.

\subsection{Aprendizagem significativa em Libras}

As perguntas finais do questionário estão relacionadas com a aprendizagem significativa na disciplina de Libras e buscam avaliar como o futuro professor se sente em relação ao atendimento de alunos surdos em sala de aula. Quando indagados sobre a disciplina de Libras, no curso de Licenciatura em Educação do Campo, 22 (44\%) declararam que a disciplina "Preparou, mas não se sentiam seguros", outros 17 (34\%) assinalaram que "Preparou em parte, para atender o aluno surdo em sala" e outros 8 (16\%) que "Não preparou". Apenas 3,6\% dos alunos disseram que a disciplina contemplou suas expectativas, pois "Preparou satisfatoriamente" como demonstrado na Figura 4. 
Figura 4. A percepção de universitários em relação à preparação das aulas na disciplina de Libras no curso de Licenciatura em Educação do Campo do CRMB, IFPA.

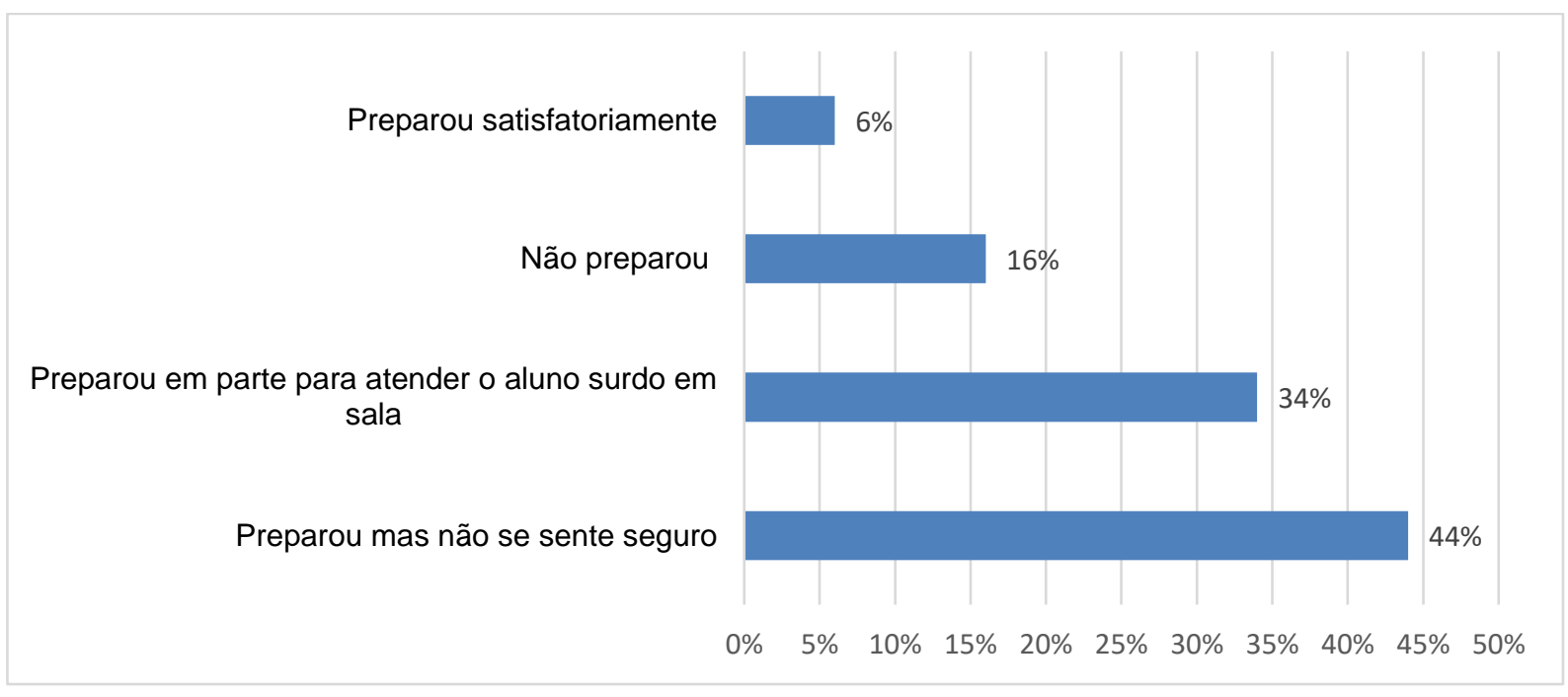

Fonte: elaborado pelos autores com base nos dados da pesquisa.

Esse resultado expõe as percepções dos estudantes da graduação em relação à inclusão de alunos surdos em sala de aula, após cursarem a disciplina de Introdução ao Ensino de Libras, demonstrando uma série de lacunas que precisam ser preenchidas, pois embora a disciplina os prepare, ainda se sentem inseguro para atuar na inclusão.

Nesse aspecto, o Plano de Curso da disciplina prevê uma carga horária de 60 horas, atende à legislação sobre inclusão e ao Decreto Lei $\mathrm{n}^{\circ}$ 55.626, mas 36\% (18) dos graduandos acreditam que, em relação à carga horária da disciplina, "Foi suficiente em parte, porque não abordou todos os conteúdos da ementa" e 16 deles (32\%) afirmam ter sido "insuficiente porque não abordou todos os conteúdos da ementa". Discordaram desse ponto de vista 6 participantes, ou seja, $12 \%$, afirmando que "Foi plenamente suficiente, pois abordou todos os conteúdos da ementa". Igual percentual disse que "Foi suficiente em parte, mesmo abordando todos os conteúdos da ementa”. Apenas 8\%, 4 estudantes dos 50 participantes se disseram satisfeitos, pois a carga horária do curso "Foi plenamente suficiente, mas não abordou todo conteúdo da ementa", conforme mostra a Figura 5. 
Figura 5- Opinião dos alunos sobre a carga horária da disciplina de Libras no curso de Licenciatura em Educação do Campo do CRMB, IFPA, 2018.

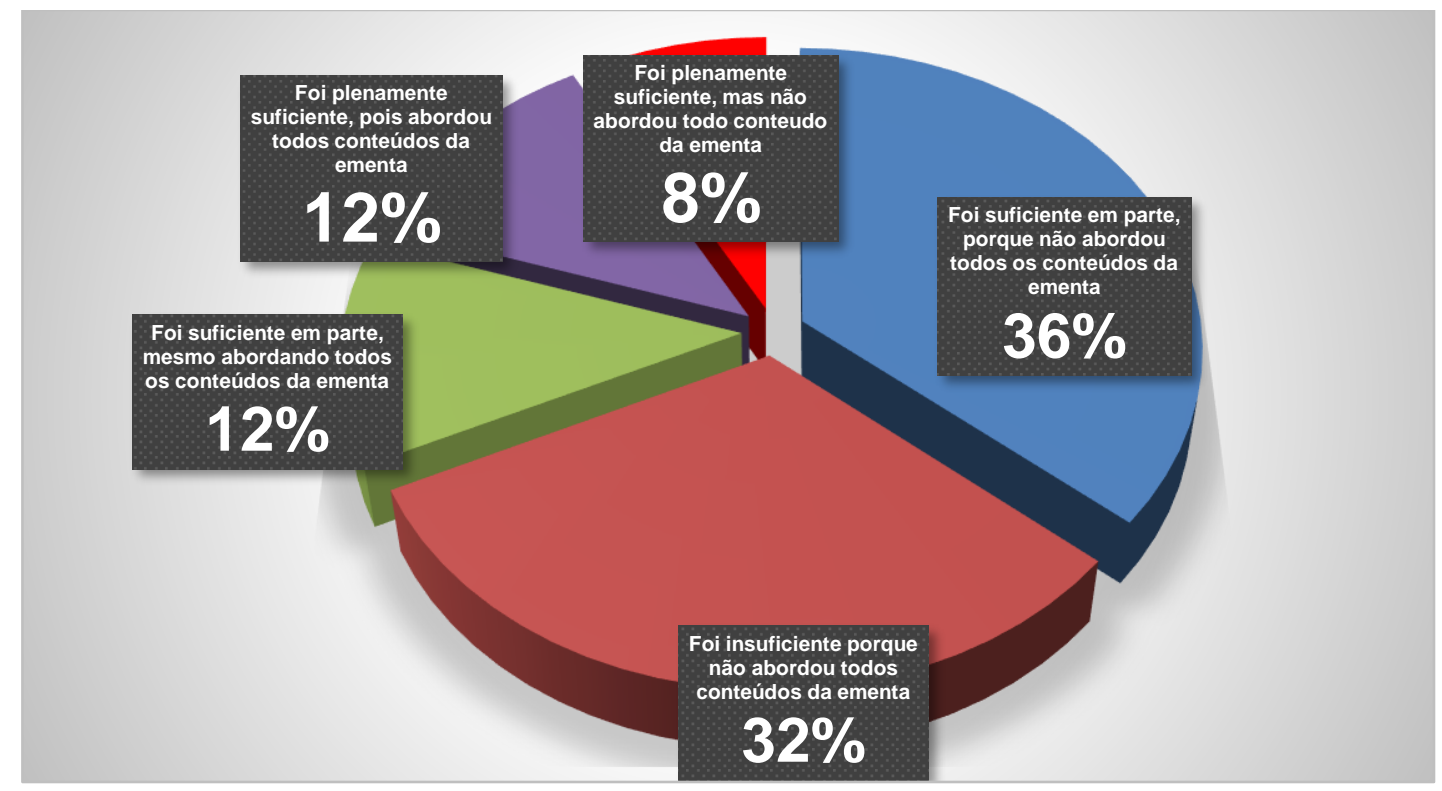

Fonte: elaborado pelos autores com base nos dados da pesquisa.

Em relação a todos os resultados, ainda foi aplicado o Teste Qui-quadrado para saber ser existiam diferenças representativas entre as repostas dadas por alunos e alunas, adotando o Grau de Liberdade 1. Apenas as repostas à pergunta sobre o processo de inclusão nas escolas brasileiras, em atendimento ao que estabelece a legislação, foram divergentes. Os estudantes do sexo masculino concordaram que o processo de inclusão brasileiro atende aos preceitos estabelecidos na legislação $\left(x^{2}=15,90\right)$, demonstrando diferenças representativas entre as repostas nesse quesito. Os indivíduos pertencentes às amostras (gêneros masculino e feminino) reagiram de modo diferente à indagação do questionário, havendo influência de um dos gêneros sobre o resultado da observação. Nesse caso, o resultado obtido dependeu especificamente do gênero masculino, com p valor $<0.0001$.

Esses resultados, portanto, responderam ao problema inicial levantado: a obrigatoriedade da disciplina de Libras nos cursos de formação de professores elimina a insegurança desses futuros profissionais em trabalhar com alunos surdos? Obteve-se resposta negativa para a pergunta, em relação à população estudada. 
Além disso, confirmou-se a Hipótese inicial de que a disciplina de Libras nos cursos de licenciatura, de forma geral, e em Educação do Campo, de forma particular, oferece conhecimentos básicos de Libras. Sua carga horária, porém, analisada no presente estudo, não se mostra suficiente, pois não contempla as necessidades de formação dos futuros professores, conforme os indicadores analisados.

\section{Considerações finais}

O estudo verificou a percepção dos estudantes do curso de Licenciatura em Educação do Campo, do IFPA, no Campus Rural de Marabá, em relação à disciplina Introdução ao Ensino de Libras. Alguns alunos pesquisados acreditam que essa disciplina prepara o futuro docente para atuação com aluno surdo em sala de aula, mas grande parte afirmou não se sentir com segurança em relação a este processo inclusivo.

Embora o plano do curso e a carga horária atenda a legislação vigente, como ocorre com o currículo de outras instituições de ensino superior no país, uma parcela significativa dos estudantes a considera insuficiente, pois não permite contemplar todos os conteúdos previstos na ementa do curso. Segundo eles, esse é um dos principais entraves para um melhor aproveitamento da disciplina.

De modo geral, percebe-se que essa disciplina precisa ser constantemente reavaliada quanto sua efetividade, dada a necessidade de tornar-se cada vez mais eficaz, considerando-se a necessidade de formação de futuros professores aptos para lidar com alunos surdos na escola inclusiva.

O estudo serve ainda para apontar a necessidade de se monitorar e até rever as práticas de formação de professores, sobretudo no que diz respeito aos processos inclusivos. A sugestão é que sejam mais eficientes. Por exemplo, a inclusão do surdo deveria ser trabalhada também em outras disciplinas e não de forma isolada em uma única disciplina durante todo o percurso formativo do futuro professor, como tem acontecido. 


\begin{abstract}
The objective of this paper is to record the perception of students from a class in the course of Teacher Training in Rural Education, in relation to the discipline Introduction to the Teaching of Libras (Brazilian Sign Language). A questionnaire on the theme was applied in order to investigate the main barriers for the teacher to act in the inclusion of deaf students in the classroom. The research showed that, for the majority of these students, their first contact with Libras happened at school, and the process of inclusion did not happen as established by the Brazilian legislation, especially because of the lack of professionals in the area and the adequate teacher education and training to work with deaf students. It was also observed that, although the workload meets the demands of the current legislation, it is insufficient, because it does not allow the application of the contents provided in the syllabus, thus becoming one of the obstacles to better experience the discipline.
\end{abstract}

Keywords: Libras. Rural education. Undergraduate. Inclusion.

\title{
Referências
}

BRASIL. Decreto lei no 5626 de 22 de dezembro de 2005. Regulamenta a Lei no 10.436, de 24 de abril de 2002, que dispõe sobre a Língua Brasileira de Sinais - Libras, e o art. 18 da Lei no 10.098, de 19 de dezembro de 2000. Diário Oficial [da] República Federativa do Brasil, Brasília, 2005.

Censo da Educação Superior 2016: notas estatísticas. Ministério da Educação(MEC)- Instituto Nacional de Estudos e Pesquisas Educacionais Anísio Teixeira (Inep). Brasília-DF, 2016. Disponível em http://download.inep.gov.br/ educacao_superior/censo_superior/documentos/2016/notas_sobre_o_censo_da_educacao_sup erior_2016.pdf, acesso em 20/11/2018, 15h

Lei $\mathrm{n}^{\circ} 10.436$ de 24 de abril de 2002. Dispõe sobre a Língua Brasileira de Sinais Libras e dá outras providencias. Diário Oficial da União, Brasília, 2002. Disponível em: < http://www. planalto.gov.br/ccivil_03/leis/2002/110436.htm>. Acesso em: 19 jul. 2018.

. Lei n ${ }^{\circ}$ 9.394, de 20 de dezembro de 1996. Estabelece as Diretrizes e Bases da Educação Nacional. Diário Oficial da União, Brasília, 1996. Disponível em: < http://www.planalto.gov.br/ ccivil_03/leis/19394.htm>. Acesso em: 20 jul. 2018.

Ministério da Educação. Secretaria de Educação Especial. Saberes e Práticas da Inclusão: Recomendações para a Construção de Escolas Inclusivas. Brasília: MEC/SEESP, 2005.

Ministério da Educação. Diretrizes Nacionais para a Educação Especial na Educação Básica. Secretaria de Educação Especial. Brasília: MEC/SEESP, 2001. Disponível em: portal.mec.gov.br > seesp > arquivos > pdf > diretrizes. Acesso em: 12 ago 2019. 
GUARINELLO, Ana Cristina. et al. A inserção do aluno surdo no ensino regular: visão de um grupo de professores do Estado do Paraná. Revista Brasileira de Educação Especial. 2006. Disponível em: http://www.scielo.br/scielo.php?script=sci $\quad$ arttext\&pid=S14135382006000300003\&lng=pt\&nrm= iso . Acesso em: 25 de jul. de 2018

LOURENÇO, Kátia Regina Conrad. Currículo Surdo: Libras na escola e desenvolvimento da Cultura Surda. Tese de Doutorado em Educação. PUC-SP, 2007.

MARCONI, M. A.; LAKATOS, E. M. Fundamentos de metodologia científica. 7. ed. São Paulo: Atlas, 2010.

MARTINS, V.R.O. O acontecimento do ensino de libras - diferenças e resistências. In: ALBRES, N.A. Libras em estudo:ensino-aprendizagem. São Paulo: FENEIS-SP, 2008.

MERCADO, E.A. O significado e implicações da inserção de libras na matriz curricular do curso de pedagogia. In: ALBRES, N.A. Libras em estudo:ensino-aprendizagem. São Paulo: FENEIS-SP, 2012.

PROJETO POLÍTICO PEDAGÓGICO. Curso de Graduação em Licenciatura Plena em Educação do Campo. Área de Concentração: Ciências Humanas e Socias. Plano Nacional de Formação de Professores do Estado do Pará- Pafor/Pará, 2007.

REILY, L. Escola Inclusiva: Linguagem e mediação. Campinas, SP: Papirus, 2004.

ROSSI, R.A.A Libras como disciplina no ensino superior. Revista de Educação.v, 13, n. 15, Anhanguera Educacional, Valinhos-SP, 2010. Disponível em: http://www.pgsskroton.com.br/ seer/index.php/educ/article/viewFile/1867/1772]. Acesso em: 20 Set. de 2018.

SOUZA, R. M de. Língua de sinais e escola: considerações a partir do texto de regulamentação da língua brasileira de sinais. In: Revista ETD (Educação Temática Digital). Vol. 7. №. 2, 2006, p. 263-278.

VITALIANO, Célia Regina. Análise dos currículos dos cursos de Pedagogia das universidades públicas dos Estados do Paraná e de São Paulo, em relação à formação para inclusão e/ou atuação junto a alunos com necessidades especiais antes e após as diretrizes curriculares de 2006. Projeto cadastrado na PROPPG. UEL. Londrina, 2009. 